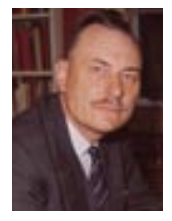

\title{
The price of poor pandemic communication
}

\author{
PERSONAL VIEW Thomas Abraham
}

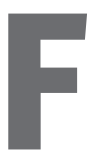
uelled by public distrust, a season of inquiries has begun into how governments and public health agencies responded to the $\mathrm{A} / \mathrm{H} 1 \mathrm{~N} 1$ influenza pandemic. If these reviews are to be meaningful, they would do well to address the failures in communication both before and during the pandemic that helped create this public distrust.

The principal failure was this: instead of using the tools and principles of risk communication to create public understanding of the risks posed by a pandemic, experts and policy makers used another form of communication, advocacy, which is intended not so much to create understanding but to persuade the public to take certain actions.

These advocacy efforts were spurred by the events of late 2003 and 2004 when, with SARS (severe acute respiratory syndrome) fresh in everyone's memory, H5N1 outbreaks emerged in poultry and humans in different parts of Asia. These outbreaks seemed to flu specialists and other public health experts a threat for which governments and the public needed to prepare. The public (and governments, except for public health agencies) were initially apathetic. And so there seemed to be a need to ring alarm bells to wake the public from its slumber and urge pandemic preparedness. Two well known risk communications consultants, Peter Sandman and Jody Lanard, captured the spirit of the times when they wrote of the feeling among infectious diseases experts of "a sense of impending disaster, a need to sound the alarm, alienation and frustration that people don't get it."

The spread of the virus, the high mortality rates in human cases, ${ }^{1}$ and the attendant media coverage created a more receptive public environment for messages about the dangers posed by H5N1. Communication messages focused on the severe human and economic costs of a pandemic, and in order to rouse governments and the public the 1918 pandemic-rather than the 1957 and 1968 pandemics-was used as an example to demonstrate how terrible it could be. These efforts began to pay off and the perception of a pandemic as a catastrophic event began to take root in the public mind.

The pandemic that emerged in 2009 was different from what the public had grown to expect from pre-pandemic communication. It arose not from an avian virus in southeast Asia, but from a swine originated virus in central America. Its severity and global impact were far less than had been expected. This gap between reality and prediction has produced a public backlash, with people questioning the competence and motivation of public health agencies, and a suspicion of the advice that is coming from them, including on vaccines.

Risk communication to create a public dialogue on the risks of a pandemic, rather than advocacy based on appeals to fear, would have been the correct approach to have used in the pre-pandemic phase. There is confusion in the public health community about the aims and goals of risk communication. It is about building a shared understanding with the public, about the nature of a risk and the measures needed to respond to it through dialogue. It is not about trying to persuade people. As a landmark study by the US National Research Council in 1989 put it, the aim of risk communication is not for the audience to accept the views or arguments of the communicator, but to raise the level of understanding so that all those who are involved are adequately informed within the limits of available knowledge.

The experience of pre-pandemic risk communication shows why risk communication should be limited to providing information about risk, rather than attempting advocacy.

The communication of risk is about the communication of uncertainty: risks are events that are likely to occur in the future, but are by no means certain to do so. Any measures taken to mitigate future risks, whether a pandemic or natural disasters, have to be based on a shared understanding between those who have technical and scientific knowledge of the risk, and those who have to bear the risk, and take actions to mitigate it. This can happen only through a two way exchange of information that will contribute to a public understanding of the risk.

In the continuous building up of the scenario of a dangerous pandemic the scientific uncertainty that surrounded these predictions was never adequately conveyed. This was not because the scientists and policy makers were unaware of the uncertainty, but because they tended to downplay uncertainties for fear that advocacy for actions like pandemic preparedness would be compromised. A conflict existed between the needs of advocacy and the needs for transparent risk communications.

If any of the ongoing inquiries into pandemic management lead to greater efforts to understand the complexities of risk communication not merely during a global public health event, but also in the preparatory phases, they would serve a useful purpose. Thomas Abraham, Public Health Communication Programme, Journalism and Media Studies Centre, University of Hong Kong thomas@hku.hk

1 WHO. Epidemiology of WHO-confirmed human cases of influenza A(H5N1) infection. Wkly Epidemiol Rec 2006;81:249-57.

Cite this as: BMJ 2010;340:C2952

See FEATURE, p 1274 